\title{
Caracterización de población con discapacidad visual, auditiva, de habla y motora para su vinculación a programas de pregrado a distancia de una universidad de Colombia
}

\author{
Characterization of a Population with Visual, Auditory, Speech and Motor Disabilities, for Their \\ Linking to Undergraduate Programs at a University in Colombia
}

\section{Caracterização da população com deficiência visual, auditiva, motora e de linguagem, para sua integração aos programas de graduação a distância de uma universidade na Colômbia}

Luz Myrian Rojas-Rojas' Universidad Pedagógica y Tecnológica de Colombia

Tunja, Colombia

miryan.rojas@uptc.edu.co http://orcid.org/0000-0002-7731-3676

Nestor Arboleda-Toro ${ }^{2}$
Asociación Colombiana de Instituciones de Educación Superior con Programas a Distancia
Bogotá, Colombia
nestorarboleda.interconed@gmail.com
http://orcid.org/0000-0002-5697-6112

Leidy Johanna Pinzón-Jaime 3 Universidad Pedagógica y Tecnológica de Colombia

Tunja, Colombia

leidy.pinzonjaime@uptc.edu.co http://orcid.org/0000-0001-8580-2798

\begin{abstract}
${ }^{1}$ Magíster en Educación de la UPTC, docente de la UPTC desde 9 años en la Facultad de Estudios a Distancia, Escuela de Ciencias Humanísticas y de Educación de la UPTC. Con amplia experiencia administrativa en sector educativo como coordinadora académica en educación secundaria y media, directora del Centro de Gestión de Investigación y Extensión CIDEA de la UPTC, directora de la Escuela de Ciencias Humanísticas y de Educación. Integrante del grupo de investigación: Saberes interdisciplinares en construcción (SIEK), línea de investigación: Desarrollo educativo y social, de la Licenciatura en Educación Básica con énfasis en Matemáticas, Humanidades y Lengua Castellana. Algunas investigaciones adelantadas son: Pertinencia de oferta de programas de pregrado; Incidencia de la práctica pedagógica investigativa de profundización de los maestros en formación en educación básica y Diseños de currículos para inclusión educativa en educación superior.

${ }^{2}$ Comunicador Social de la Universidad Javeriana y especialista en Pedagogía de la Virtualidad de la Fundación Universitaria Católica del Norte de Colombia. Actualmente es director ejecutivo de la Asociación Colombiana de Instituciones de Educación Superior con Programas a Distancia, ACESAD; director académico de la Alianza Fundación Círculo de Excelencia Académica, FUNCEA e Instituto Internacional de Consultoría Pedagógica y Estudios a Distancia, INTERCONED; y es miembro del Comité Científico del Congreso Iberoamericano sobre Calidad de la Formación Virtual, con los auspicios de Virtual Educa, que se celebra en la Universidad de Alcalá, Alcalá de Henares, España. Ejerció como vicerrector de Educación Virtual y a Distancia de la Corporación Unificada Nacional de Educación Superior, CUN (desde el año 2000 hasta 2010) y en representación de esta, secretario general de ACESAD, como director de Capacitación a Distancia de la Academia Diplomática, Ministerio de Relaciones Exteriores. (1992 al 2000) y decano de la Facultad de Ciencias y Educación de la Universidad Distrital de Bogotá (1987). Autor de 10 libros en las áreas de educación virtual y a distancia, tecnología educativa, diseño instruccional, innovaciones pedagógicas, metodología y estrategias en los sistemas de aprendizaje abierto, nuevo enfoque estratégico de la negociación y resolución pacífica de conflictos, capacitación interactiva de funcionarios públicos.

${ }^{3}$ Licenciada en Educación Básica con Énfasis en Matemáticas, Humanidades y Lengua Castellana de la UPTC. Actualmente asesora externa de grupos de investigación de la FESAD de la UPTC, ejerció por 7 años como asistente técnica del Centro de Investigaciones de la Universidad Santo Tomás de Tunja, institución en la cual coordinó el proceso de indexación de 5 revistas especializadas. Es asistente editorial en la publicación de libros impresos y digitales Se desempeña como asesora independiente en procesos de acreditación de programas de educación superior. Organiza eventos de investigación de alto nivel con la participación de científicos de reconocimiento mundial. Autora de ponencias sobre inclusión educativa, coautora del capítulo de libro La investigación en la Universidad Santo Tomás. Asesora la metodología para la elaboración de tesis de grado y posgrado a estudiantes de diferentes universidades. Sus proyectos y actividades se enmarcan en las líneas de investigación de apropiación social del conocimiento, educación y pedagogía.
\end{abstract}


doi: http://dx.doi.org/10.15359/ree.22-1.6

URL: http://www.una.ac.cr/educare

CORREO: educare@una.cr

Recibido • Received • Recebido: 04 / 06 / 2016

Corregido • Revised • Revisado: 25 / 09 / 2017

Aceptado • Accepted • Aprovado: 18/10/2017

Resumen: En este artículo se socializan los resultados de la investigación inédita que tuvo por objetivo caracterizar la población en situación de discapacidad visual, auditiva, de habla y motora, en la que se cuantificó público usuario potencial para los programas que ofrece la Facultad de Estudios a Distancia (FESAD) de la Universidad Pedagógica y Tecnológica de Colombia (UPTC). El diseño metodológico fue descriptivo exploratorio con selección aleatoria de la muestra; se aplicaron encuestas, en sistema braille y traductor digital de lengua de señas, a estudiantado de bachillerato de personas jóvenes y a personas adultas bachilleres. Se utilizó el método estadístico cuantitativo para el análisis de datos. Los resultados muestran que, del grupo de bachilleres jóvenes, el 53\% son mujeres; el $51 \%$ del grupo adulto son hombres; $57 \%$ del de jóvenes está entre los 18 y $21 ; 47 \%$ del de personas adultas entre los 22 y 30 años y $65 \%$ no trabaja. De las áreas de preferencia para estudiar un $28 \%$ de jóvenes prefieren ingenierías, $21 \%$ ciencias económicas y administrativas, $15 \%$ artes y $13 \%$ ciencias de la educación. El 27\% del grupo adulto prefiere ingeniería, 18\% ciencias económicas y administrativas, $15 \%$ ciencias de la educación. El $85 \%$ del joven y el $71 \%$ del adulto son personas con sordera. Se concluye que hay una población vulnerable en condición de discapacidad con evidente falta de oportunidades de acceso a la educación superior, así mismo que la FESAD ha capacitado a docentes en el diseño de un currículo integrado e integrador para el desarrollo de competencias laborales y posee los recursos técnicos-tecnológicos para atenderles. Se recomienda dinamizar las políticas de educación superior para la inclusión social en Colombia y adelantar nuevos estudios que indaguen las causas y efectos para diseñar e implementar programas que las apliquen.

Palabras clave: Educación superior; discapacidad; distancia; virtual; inclusión.

Abstract: This article presents the results of an unpublished research project whose objective was to characterize a population with visual, hearing, speech and motor disabilities. The research quantified potential users of the programs offered by the Faculty of Distance Education (FESAD) at the Pedagogical and Technological University of Colombia (UPTC). It had an exploratory-descriptive methodological design with random sampling. Surveys were applied to young high school students and adult bachelors by using Braille system and a digital sign language translator. For data analysis, a quantitative statistical method was implemented. The results showed that, from young bachelors, $53 \%$ were women, $51 \%$ adults were men; $57 \%$ of young people were between 18 and 21 years old, $47 \%$ of adults were between 22 and 30 years old, and $65 \%$ of adult bachelors did not work. From the preferred university careers to study, a $28 \%$ of young people preferred engineering; $21 \%$, economic and administrative sciences; $15 \%$, arts; and 13\%, education sciences. $27 \%$ of adult bachelors preferred engineering; $18 \%$, economic and administrative sciences; and 15\%, education sciences. $85 \%$ of youth and $71 \%$ of adult bachelors were deaf. It is concluded that there is a vulnerable population with disabilities and with an obvious lack of opportunities to access higher education. FESAD has trained teachers in designing an integrated and inclusive curriculum for the development of labor skills. FESAD also has technical and technological resources to take care of this population. It is recommended to boost higher education policies for social inclusion in Colombia, and conduct new studies on causes and effects to design and implement programs that apply these policies.

Keywords: Higher education; disability; distance; virtual; inclusion.

2 Luz Myrian Rojas-Rojas, Nestor Arboleda-Toro y Leidy Johanna Pinzón-Jaime 
Resumo: Neste artigo, publica-se os resultados de uma pesquisa inédita cujo objetivo foi visualizar e caracterizar a população em situações de deficiência visual, auditiva, motora e de linguagem, na qual se quantificou o público utilizador potencial dos programas que oferece a Faculdade de Estudos a distância (FESAD) da Universidade Pedagógica e Tecnológica da Colômbia (UPTC). O desenho metodológico foi exploratório descritivo com seleção aleatória da amostra; aplicamos questionários, em Braille e tradutor digital de língua de sinais, a estudantes jovens de bacharelato e a pessoas adultas que já são formadas nesse grau. Foi utilizado o método estatístico quantitativo para a análise de dados. Os resultados mostram que, do grupo de jovens bachareles, $53 \%$ são mulheres; $51 \%$ do grupo adulto são homens; $57 \%$ dos jovens têm entre 18 e 21 anos; $47 \%$ dos adultos entre 22 e 30 anos e 65\% não trabalham. Das áreas de preferência para estudar 28\% dos jovens preferem engenharia, 21\% ciências econômicas e administrativas, $15 \%$ artes e 13\% Ciências da educação. 27\% do grupo adulto prefere engenharia, 18\% ciências econômicas e administrativas, $15 \%$ Ciências da educação. $85 \%$ dos jovens e $71 \%$ dos adultos são surdos. Conclui-se que há uma população vulnerável e em condições de deficiência, com evidente falta de oportunidades para o acesso ao ensino superior, do mesmo modo que a FESAD formou à professores na concepção de um currículo integrado e integrador para o desenvolvimento de competências laborais e tem os recursos técnicos-tecnológicos para atendê-los. Recomenda-se dinamizar as políticas de educação superior para a inclusão social em Colômbia e avançar novas pesquisas que buscam determinar suas causas e os efeitos, para pensar e propor programas que os apliquem.

Palavras-chave: ensino superior, deficiência, distância, virtual, inclusão.

\section{Introducción}

"La inclusión pone particular énfasis en aquellos grupos de alumnos que podrían estar en riesgo de marginalización, exclusión, o fracaso escolar" (Echeita y Ainscow 2011, p. 34). Lo anterior implica que los grupos que están en condición de vulnerabilidad engrosan las estadísticas, por lo que deben ser supervisados y tomar las medidas necesarias para garantizar su presencia, su participación y su éxito en el sistema educativo.

Las estadísticas muestran que más de mil millones de personas en todo el mundo padecen alguna discapacidad física o cognitiva, lo que equivale a cerca del $15 \%$ de la población mundial. De este total, existen en América Latina y el Caribe cerca de 85 millones de personas en situación de discapacidad, con el agravante de que estas cifras van en aumento en muchos de los países de la región debido, primordialmente, al envejecimiento de la población, al incremento de las enfermedades crónicas y a las incidencias de los fenómenos de violencia que se presentan en diversas partes del mundo (Gómez, 2010; Organización Mundial de la Salud [OMS] y Banco mundial [BM], 2011).

A nivel internacional, de acuerdo con datos estadísticos del Banco Interamericano de Desarrollo (Departamento Administrativo Nacional de Estadísticas, DANE, 2006), Colombia es el segundo país con mayor prevalencia de discapacidad cuyo porcentaje es del $6.4 \%$, después de Brasil (14.5\%), seguido de Costa Rica (5.4\%), Barbados (4.6\%), Trinidad y Tobago (4.5\%) y Venezuela (4.1\%). 
doi: http://dx.doi.org/10.15359/ree.22-1.6

URL: http://www.una.ac.cr/educare

CORREO: educare@una.cr

A partir de la precisión sobre el número de personas en Colombia con por lo menos una limitación física o cognitiva, el Censo general de población realizado por el (DANE, 2006) estableció para el país una prevalencia de discapacidad del 6,4\% que equivale a 2.632 .255 personas, teniendo en cuenta que para ese año la población total del país era de 41.242.948. De este total, el Censo identificó el número de personas y porcentaje de prevalencia de la respectiva situación de discapacidad en el país: personas con limitaciones para ver 43,2\% (1.143.992), con limitaciones para caminar 29,5\% (770.128), para oír 17,4\% (454.822), para usar brazos y manos $14,9 \%$ (387.598), para hablar 13,2\% (340.430), para entender y aprender 12,3\% (315.601), para relacionarse con las demás 10,1\% (257.573), para su autocuidado 9,8\% (247.113), otra limitación $18,8 \%$ (494.683).

Hay en la anterior relación un número considerable de personas que no pueden oír ni hablar, que complementa las cuatro categorías de población en situación de discapacidad a las que va dirigido el estudio: visual, auditiva, de habla y motora. Esta situación presenta importantes diferencias regionales, debido a que, mientras en el promedio nacional por cada 100 personas colombianas 6,4 presentan limitaciones permanentes, hay siete departamentos en los que este promedio es más alto, fluctuando entre $9.5 \%$ en el Cauca y $7.8 \%$ en el Tolima (DANE, 2006).

Si se mantiene el promedio porcentual de prevalencia de la discapacidad establecido por el DANE (2006), en el último censo general de población adelantado en 1098 municipios y 20 corregimientos departamentales, al proyectar las estadísticas a la actual población de Colombia, calculada en cerca de 48 millones de habitantes, nos da una cifra cercana a los 3 millones de personas en situación de discapacidad. Pero si tenemos en cuenta el promedio del 15\% calculado a nivel internacional por la OMS y BM (2011), la cifra de personas en situación de discapacidad en Colombia asciende a más de 7 millones.

Para los efectos de este estudio, conviene resaltar que, de acuerdo con las estadísticas oficiales, del total de personas en situación de discapacidad, el mayor porcentaje corresponde a la población adulta en términos generales, cuyo total se comparte en proporciones iguales entre menores de 62 años y a mayores de 62 años en adelante.

Al evaluar por sexo la anterior situación, la discapacidad es mayor en hombres (6.6\%) que en mujeres (6.1\%), excepto en el grupo de 85 años y más. Así, en el grupo de 50 a 54 años, el $10,6 \%$ de hombres y el 10,1\% de mujeres presentan limitaciones permanentes, mientras que, en el grupo de 80 a 84 años, es el 38,3\% de hombres y el 37,6\% de mujeres quienes presentan esta condición (DANE, 2006). Según Gómez (2010), uno de cada tres individuos colombianos en condición de discapacidad no cuenta con afiliación al sistema general de seguridad social en salud, el $34 \%$ de la población con discapacidad se encuentra excluida de su derecho a la educación y refieren su condición de discapacidad como causa de su exclusión. El 94.4\% se encuentra en edad de trabajar, pero el $80 \%$ no trabaja. 
En esta dirección avanzan las acciones estratégicas que buscan alcanzar la meta que, al respecto, se trazó el Plan Nacional de Desarrollo (PND) 2010-2014, en el que se considera la discapacidad como una situación socialmente problemática y multidimensional, con fuertes implicaciones políticas, económicas, sociales, culturales y educativas en general; pero en la educación superior, de manera específica, se inscribe la investigación adelantada y la correspondiente propuesta de formación profesional (Departamento Nacional de Planeación, DNP, 2010).

Así mismo, el acceso a la educación superior es bajo a nivel mundial. Durante la primera década del siglo XXI, se prendieron las alarmas en Colombia en relación con la garantía de educación para las personas en situación de discapacidad, cuestionada por varios estudios sobre su carácter inequitativo y excluyente. En uno de estos estudios se resalta que los niños, niñas, adolescentes y jóvenes con discapacidad tienen menos posibilidades de ingresar a los planteles educativos de preescolar, educación básica y media, de permanecer en ellos y de avanzar en su proceso de formación. Esta decreciente participación en el sistema educativo se ve reflejada en el acceso a la educación superior de la población con discapacidad que en Colombia se estima es solo del 5.4\% (Sarmiento, 2011).

Gómez (2010) establece que existen diferencias en el nivel educativo alcanzado por las personas registradas: a mayor exclusión en capital humano, mayor proporción de personas con ningún nivel educativo, al igual que con primaria incompleta; mientras que la primaria completa, secundaria y grados superiores presentan una mayor proporción de población en los departamentos de menor exclusión. Los datos muestran una escasa oportunidad de formación en todos los niveles de exclusión en capital humano, lo que conlleva a una baja cualificación laboral. La investigación adelantada por Molina (2010) da cuenta del bajo nivel de estudiantes en condición de discapacidad que se han vinculado a programas de universidades públicas y privadas colombianas; pero también deja en manifiesto que el Ministerio de Educación realiza esfuerzos para promover la política de acceso, permanencia y culminación de los estudios en educación superior de la población con discapacidad, en condiciones de equidad en cumplimiento de convenios internacionales.

En esta misma línea, la investigación adelantada por Serrano y Camargo (2011), muestra que acudientes de las personas discapacitadas expresaron que hay aspectos que imponen barreras como los altos costos de matrícula y pensiones (70,6\%), la ubicación alejada de las instituciones educativas $(64,7 \%)$ y las dificultades en la disponibilidad de transporte $(55,9 \%)$, lo cual puede tener relación con el nivel de ingreso económico, puesto que la mayoría son de estratos 1 y 2 , lo que conlleva a "una pobre oportunidad de formación y un rango estrecho de cualificación laboral" (p. 296). 
doi: http://dx.doi.org/10.15359/ree.22-1.6

URL: http://www.una.ac.cr/educare

CORREO: educare@una.cr

La marcada ausencia del servicio educativo de jóvenes y personas adultas de esta población vulnerable y el consiguiente impacto socioeconómico de esta situación constituyen el punto focal del presente estudio. De otro lado, en el documento de política pública para la educación superior presentado en 2014 por el Consejo Nacional de Educación Superior, CESU, denominado Acuerdo por lo Superior 2034, se plantean los grandes cursos de acción prioritaria que debe asumir Colombia en esta materia durante las próximas dos décadas (Consejo Nacional de Educación Superior, CESU, 2014). Dentro de los diez temas esenciales propuestos en la agenda para alcanzar el objetivo común de una educación superior de calidad para toda la población colombiana aparece, en primer término, la educación inclusiva: acceso, permanencia y graduación.

La exigencia de pensar la educación superior como un derecho se centra ahora de manera prioritaria en los cinco grupos que mayores dificultades tienen de disfrutar los beneficios de este nivel educativo por circunstancias sociales, económicas, políticas, culturales, lingüísticas, físicas y geográficas, de acuerdo con el estudio del Centro de Investigaciones para el Desarrollo de la Universidad Nacional de Colombia (2007, citado en CESU, 2014), con el apoyo del Ministerio de Educación Nacional:

- Personas en situación de discapacidad y con capacidades o talentos excepcionales.

- Grupos étnicos: comunidades negras, afrocolombianos, raizales y palenqueros, indígenas y Rom.

- Población víctima, según lo estipulado en el artículo tercero de la Ley 1448 de 2011.

- Población desmovilizada en proceso de reintegración.

- Población habitante de frontera. (p. 94)

Allí se expresa que el sistema de educación superior colombiano es uno de los principales ejes de la transformación y de la movilidad social, base del desarrollo humano sostenible, social, académico, científico, económico, ambiental y cultural de nuestro país.

Y es clara su visión: "para el año 2034 el sistema de educación superior será uno de los pilares sobre los cuales los colombianos habremos construido una sociedad en paz (justa, culta, democrática, solidaria, próspera, competitiva e incluyente), en la que convivan digna y pacíficamente ciudadanos libres, éticos, responsables y productivos" (CESU, 2014).

Se trata entonces de que se pueda educar con éxito a la diversidad de su alumnado, y aportar en la reducción de la desigualdad e injusticia sociales, especialmente en las instituciones universitarias donde hasta ahora empieza a transitarse el camino hacia la inclusión educativa, la multiculturalidad y a reconocer allí la diversidad en todas sus expresiones. (Parra, 2011 p. 149) 
Por lo expuesto hasta aquí, se colige que las cifras de la población que se encuentra en condición de discapacidad al margen de acceder, permanecer y concluir su proceso formativo en igualdad de oportunidades y condiciones en instituciones de educación en Colombia es preocupante en los niveles de preescolar, básica y media; y, más aún, en el de educación superior, lo cual, sin duda, limita su actuación en espacios laborarles y el goce pleno de sus derechos. Aunado a lo anterior, el desconocimiento de las características y condiciones biopsicosociales de la población con discapacidad que puede beneficiarse de una oferta académica en educación superior, y las reducidas condiciones culturales, curriculares, financieras (costos de matrículas), administrativas, técnicas y de talento humano de estas instituciones limitan procesos eficaces de inclusión.

Ahora bien, teniendo en cuenta que en Colombia es evidente la falta de oportunidades de acceso a la educación superior de la población en situación de discapacidad que, aunque desee y necesite adelantar estudios de formación profesional, no puede lograrlo debido a que en general la oferta académica no se adecua a sus necesidades y exigencias y que son mínimas las investigaciones sobre caracterización de población vulnerable en educación superior, surge la necesidad de aportar este estudio por la Facultad de Estudios a Distancia (FESAD) de la Universidad Pedagógica y Tecnológica de Colombia (UPTC). El propósito es facilitar su acceso a la educación superior en la modalidad a distancia y virtual, en vista de que la universidad cuenta no solo con los espacios y los tiempos para el desarrollo del proceso de aprendizaje, sino que, a su vez, responde y posibilita el acceso a la información y, por lo tanto, a la construcción de conocimiento. Es así como se perfila el objetivo de la investigación: caracterizar la población en situación de discapacidad visual, auditiva, de habla y motora, cuantificando usuarios potenciales para los programas que ofrece la FESAD y proporcionar información valiosa como referente para próximas investigaciones, para la toma de decisiones por parte de las entidades territoriales y de la universidad, con el fin de dinamizar las políticas de educación superior para la inclusión social y educativa en Colombia.

\section{Marco conceptual}

\section{La discapacidad en Colombia}

El estudio de este importante tema en Colombia implica reconocer la existencia de barreras familiares, sociales, culturales y educativas que les impiden a las personas con discapacidad ser incluidas efectivamente en cada uno de los espacios que componen la sociedad. Según la Convención de la ONU (2006):

La discapacidad es un concepto que evoluciona y que resulta de la interacción entre las personas con deficiencias y las barreras debidas a la actitud y al entorno que evitan su participación plena y efectiva en la sociedad, en igualdad de condiciones con los demás. (p. 2) 
doi: http://dx.doi.org/10.15359/ree.22-1.6

URL: http://www.una.ac.cr/educare

CORREO: educare@una.cr

Se observa, en esta definición de la ONU, una concepción rehabilitadora, por cuanto hablar de deficiencia y de barreras actitudinales implica comprender el atraso y el paradigma propio de una sociedad en la que la diversidad hasta ahora está siendo incluida.

La clasificación internacional del funcionamiento de la discapacidad y de la salud (CIF), desarrollada por la Organización Mundial de la Salud, utiliza un enfoque biopsicosocial y define la discapacidad desde el punto de vista relacional que incluye deficiencias, limitaciones en la actividad y restricciones en cuanto a que a la persona con discapacidad no solamente se le debe observar desde un enfoque rehabilitador, sino que se debe tener en cuenta su componente biológico, psicológico y participación (OMS, 2001).

Ahora bien, a nivel internacional, España es uno de los países en los cuales se habla no de discapacidad o falta de capacidad para hacer algo, sino de diversidad funcional. Romañach y Lobato (2005) manifiestan que la diversidad funcional es un término que dignifica a la persona en condición de discapacidad por cuanto son muchos las mujeres y hombres que pertenecen a este segmento poblacional y que constituyen un porcentaje significativo de personas tradicionalmente discriminadas. Por lo cual, se hace necesario romper con el paradigma diferencial exclusivo para entrar en una consolidación de pensamiento inclusivo que procure el reconocimiento de todas y todos en condiciones de igualdad.

En concordancia con lo anterior, es procedente resaltar que cuando se habla de dignidad humana se está reconociendo la universalidad y, en tal sentido, hablar de diversidad funcional es quizá el primer paso que nos lleva al reconocimiento de la diversidad en condiciones de igualdad sin que haya lugar a la exclusión familiar, social y educativa. Así mismo, hablar de diversidad implica reconocer que todos los que hacemos parte del orbe tenemos alguna condición diferencial y que, por lo mismo, se deben garantizar los derechos en condiciones de igualdad y equidad.

La clasificación internacional del funcionamiento de la discapacidad y de la salud (CIF), abarca todos los aspectos de la salud y algunos componentes del bienestar relevantes para las personas en condición de discapacidad, sin que este mismo trate conceptos que se encuentren por fuera de este contexto poblacional. Esta clasificación constituye una guía importante dentro del proceso de reconocimiento de la diversidad en condiciones de igualdad.

El enfoque biopsicosocial descrito tiene su fundamento principal en la integralidad del ser humano; entiende que debe contener los aspectos biológicos, psicológicos y de contextualización social de las personas en condición de discapacidad y de sus familias, para lograr, de esta forma, un verdadero proceso de inclusión en el que la integración de factores ambientales también es parte. 
Dubet (2011) refiere que la justicia social contempla la igualdad de posiciones y la igualdad de oportunidades: la primera corresponde a las acciones para reducir las distancias; mientras que la segunda busca fijar las posiciones y asegurarlas, en el mismo sentido, alude que cada quien busca su posición en su contexto y que "sea del pueblo que sea, la escuela a la que el alumno ingrese sea idéntica a la de cualquier ciudad o pueblo vecino, que los programas y la orientación pedagógica sean los mismos" (p. 24). Así, se tendrá una igualdad de oportunidades para reducir las brechas sociales en un sistema educativo en el cual no se genere un sistema paralelo para atender a los grupos vulnerables, sino que se incluyan en los ya existentes, sin dejar de proporcionar espacios, recursos y estrategias pedagógicas que apoyen sus procesos de formación.

\section{La inclusión en el contexto de la modalidad de educación a distancia y virtual en Colombia}

Esta modalidad educativa, por sí misma ya promueve la inclusión y movilidad social, dado que permite que todo el estudiantado acceda al servicio educativo de calidad y logre terminar su formación profesional. Para tal fin se diseñan e implementan estrategias de enseñanza y aprendizaje que responden a una formación en la diversidad, con metodologías basadas en el aprendizaje autónomo y la autogestión del conocimiento, en el marco de relaciones pedagógicas asincrónicas y asincrónicas entre estudiantes, docentes e institución. En estas relaciones predomina el uso de las tecnologías de la información y las comunicaciones; de recursos, medios y mediaciones técnicos y tecnológicos que permiten romper barreras espaciotemporales, edad, condiciones políticas, sociales de género, de discapacidad entre otras, en donde perfectamente se complementa el trabajo con el proceso de formación en la cotidianidad. Las instituciones que ofertan programas a distancia realizan ejercicios indispensables inherentes a su razón de ser y a la responsabilidad social (Salazar y Melo, 2013).

\section{Políticas y normas internacionales que promueven la equidad en educación}

Si bien es cierto que dentro de los instrumentos normativos de carácter internacional que promueven la equidad en el plano educativo se aboga por los derechos de todos los grupos vulnerables por igual, se ha requerido de instrumentos específicos que den cuenta de lo particular en la atención de la población con discapacidad.

Este estudio pudo verificar que Colombia, como miembro de la ONU, se ha comprometido con la garantía del derecho a la educación, acogiendo cada una de las políticas y normas consensuadas internacionalmente, tal como se explica en seguida tomando como referencia un documento que al respecto elaboró el Ministerio de Educación Nacional, Instituto Nacional para Ciegos e Instituto Nacional para Sordos (2012): 
doi: http://dx.doi.org/10.15359/ree.22-1.6

URL: http://www.una.ac.cr/educare

CORREO: educare@una.cr

- Conferencia Mundial de Jomtien (UNESCO, 1990): por medio de la cual se realiza la Declaración para la Educación para Todos, y se fijan los objetivos, entre los cuales se destacan:

- Universalizar el acceso al aprendizaje.

- Fomentar la equidad.

- Ampliar los medios y el alcance de la educación básica.

- Mejorar el entorno del aprendizaje.

- Foro Mundial de la Educación de Dakar (UNESCO, 2000): adoptó el nombre de Educación inclusiva, el camino hacia el futuro, en sus principios fundamentales se define que la Educación para Todos (EPT) es una obligación y una prerrogativa de cada Estado, además presenta un pronunciamiento que señala la urgencia de brindar oportunidades educativas a aquellos estudiantes vulnerables a la marginación y la exclusión, entre quienes se encuentran aquellos con discapacidad.

- Metas 2021, la educación que queremos para la generación de los bicentenarios OEI: busca redoblar el esfuerzo para lograr los objetivos de la Educación para Todos en 2015; precisarlos y completarlos en función de los desarrollos y exigencias de los últimos años, adecuarlos a los ritmos de crecimiento de cada país. Este compromiso es refrendado por la Cumbre de Jefes de Estado y de Gobierno celebrada en diciembre de 2010 en Argentina. (p. 14)

- En 2006, Colombia participa en la Convención sobre los derechos de las personas con discapacidad y su Protocolo Facultativo... Esta convención resultó de gran importancia, ya que propone un cambio en la perspectiva política y social para abordar las comprensiones sobre "discapacidad" y su atención, reenfocándola desde los Derechos Humanos. ...

- Además, Colombia ratificó la Convención el 10 de mayo de 2011 (Ley 1346 de 2009), lo que le compromete a generar las condiciones para avanzar como nación, en la comprensión y puesta en práctica de los compromisos asumidos. Finalmente, en 2008, adopta la Conferencia Internacional sobre Educación (Ginebra, Suiza), denominada: Educación inclusiva..., el camino hacia el futuro. (p. 10)

\section{Normas para la atención a la discapacidad en el contexto nacional}

Los instrumentos con que cuenta la ciudadanía colombiana con discapacidad están registrados en la normatividad interna, cuya expedición concuerda con el aumento en el grado de conciencia desarrollada durante los últimos años por la población sobre las posibilidades educativas de las personas en situación de discapacidad. 
- La Constitución Política de Colombia (Asamblea Nacional Constituyente, 1991) contempla la igualdad de todos los seres humanos, la inalienabilidad de los derechos de las personas sin discriminación alguna; la protección especial a personas que, por su condición económica, física o mental, se encuentren en condición de protección especial.

- La Ley 115 (Congreso de Colombia, 1994) dedica el capítulo 1 del título Ill a la educación para personas con limitaciones o capacidades excepcionales y establece en el Artículo $46^{\circ}$ que "la educación para personas con limitaciones físicas, sensoriales, psíquicas, cognoscitivas, emocionales o con capacidades intelectuales excepcionales es parte integrante del servicio público educativo" (párr. 1), y en el mismo Artículo $46^{\circ}$ plantea que "los establecimientos educativos organizarán directamente o mediante convenio, acciones pedagógicas y terapéuticas que permitan el proceso de integración académica y social de dichos educandos" (párr. 2).

- El Decreto 2082 de 1996 (Presidencia de la República de Colombia, 1996) afirma que la atención de la población con discapacidad y con capacidades o talentos excepcionales es de carácter formal, no formal (hoy en día formación para el trabajo y desarrollo humano) e informal y que será ofrecida en instituciones educativas estatales y privadas de manera directa o mediante convenio.

- El Decreto 3020 de 2002 (Ministerio de Educación Nacional, Colombia, 2002), en el Artículo 11, establece que la entidad territorial debe atender los criterios y parámetros establecidos por el Ministerio de Educación Nacional para "fijar la planta de personal de los establecimientos ... que atienden a estudiantes con necesidades educativas especiales..." (p. 2).

- El Decreto 366 (Ministerio de Educación Nacional, Colombia, 2009), a través del cual se organizan los servicios de apoyo pedagógico para la atención del estudiantado con discapacidad y con capacidades o talentos excepcionales, en el marco de la educación inclusiva.

- La Ley 1346 de 2009 (Congreso de Colombia, 2009) por medio de la cual se aprueba y adopta la Convención de Derechos de las Personas con Discapacidad.

- La Ley Estatutaria 1618 de 2013 (Congreso de Colombia, 2013): establece las disposiciones para garantizar el pleno ejercicio de los derechos de las personas con discapacidad. 
doi: http://dx.doi.org/10.15359/ree.22-1.6

URL: http://www.una.ac.cr/educare

CORREO: educare@una.cr

\section{Metodología: Precisiones sobre el alcance y dimensiones del estudio}

La investigación se realizó como un estudio exploratorio y descriptivo con un marco conceptual, metodológico, normativo y de gestión institucional, referido a la atención a personas en situación de discapacidad. Se combinó el manejo de fuentes documentales de la Ibibliografía existente en torno al objeto de estudio, con el trabajo de campo en el que se aplicaron los instrumentos de acopio de la información, análisis de los datos estadísticos e interpretación de los resultados, mediante un sustentado procedimiento que pretende dar cuenta de este aspecto.

La decodificación de las encuestas y entrevistas fue sistematizada y sujeta a los análisis e interpretaciones correspondientes, en un procedimiento de codificación abierta que resalta el análisis de los datos, descrito por Strauss y Corbin (1990 y 1998, citados en Hernández, Fernández-Collado y Baptista, 2006), donde las categorías se basan en los datos recolectados, a las cuales se les otorgan otras propiedades representadas en subcategorías que a la vez son codificadas.

De conformidad con este planteamiento, el alcance del estudio está delimitado en dos ámbitos interrelacionados que configuran las dos dimensiones de este mismo: el diseño estadístico cuantitativo comprendió la identificación del tamaño de la población, selección de la muestra representativa, trabajo de campo, recolección y procesamiento de la información. La recolección de datos e información se llevó a cabo durante el trabajo de campo, fundamentada en la medición numérica cuyos resultados se analizaron con base en técnicas estadísticas.

Además del análisis de los resultados arrojados por el estudio cuantitativo, se utilizó como soporte adicional el enfoque cualitativo para justificar y explicar la necesidad de dar respuestas a estas demandas no satisfechas de formación por parte de poblaciones vulnerables en situación de discapacidad, corroborando así los resultados alcanzados en esta investigación. La percepción empírico-analítica permitió la comprensión y explicación del fenómeno de la discapacidad desde la dimensión del acto educativo. Se utilizaron procedimientos e instrumentos de inferencia estadística.

Como suele suceder en la práctica durante el desarrollo de este tipo de investigaciones, fue preciso adelantar primero un estudio exploratorio para aproximase a la realidad institucional que se describe tanto en lo referente a los antecedentes y situación actual de la atención de la discapacidad a nivel de la FESAD, como al estado del arte de esta problemática a nivel nacional, departamental y municipal. 


\section{Población}

Estudiantes jóvenes de bachillerato y personas adultas bachilleres en situación de discapacidad visual, auditiva, de habla y motora, q quienes se considera como público usuario potencial de los servicios de formación universitaria ofrecidos por centros regionales de educación a distancia (CREAD) en donde hace presencia la Universidad.

Las variables de edad y género de los dos grupos poblacionales se explicitan de la siguiente manera: (a) estudiantado joven próximo a terminar el bachillerato (grados $10^{\circ}$ y $11^{\circ}$ ) o de reciente graduación (menos de 3 años de haberse graduado) y (b) estudiantado adulto que terminó bachillerato hace más de tres años, que no ha podido ingresar a la educación superior y contempla, en la educación a distancia y virtual, una segunda oportunidad de profesionalización.

El universo poblacional se estudió como una unidad total de análisis, conformada por varias unidades menores, teniendo en cuenta que los sujetos que pertenecen a ellas son personas semejantes en sus características principales y en sus posibles reacciones frente a las necesidades de formación no satisfechas que pretenden solventar los programas académicos de la FESAD. Según este enfoque, dicha población total homogénea está integrada por varios segmentos particulares como unidades específicas de análisis, a saber: a) personas ciegas y de baja visión, b) personas sordas, c) personas sordo-ciegas y d) personas con discapacidad motora.

Para cuantificar el tamaño de la población total, se estableció el cálculo de acuerdo con los datos oficiales disponibles con los que se levantó el diagnóstico sobre la población estudiada, siguiendo los procedimientos estadísticos correspondientes, en orden a determinar número de público usuario potencial en cada uno de los segmentos poblacionales. Los listados, elaborados inicialmente con el concurso de las entidades del Sistema Nacional de Discapacidad, entidades gubernamentales afines a esta organización, planteles educativos y organizaciones humanitarias dedicadas a la discapacidad, fueron reelaborados, complementados y clasificados.

\section{Selección de la muestra representativa}

Se aplicó la técnica del muestreo estratificado (Mcmillan y Schumacher, 2005). Para ello se tuvo en cuenta a todas las personas dentro de cada uno de los estratos en que se había dividido la población total, se seleccionó aleatoriamente, de acuerdo con la siguiente regla estadística: un número específico de elementos se extrae de cada estrato, y corresponde a la proporción de ese estrato en la población total. Así, se buscó mantener la coherencia sobre el carácter homogéneo de la población, mediante listados ordenados en la base de datos, asegurando un adecuado nivel de representatividad de la muestra seleccionada y estableciendo una cobertura numérica equilibrada en todos los segmentos muestrales. 
doi: http://dx.doi.org/10.15359/ree.22-1.6

URL: http://www.una.ac.cr/educare

CORREO: educare@una.cr

En el trabajo de campo se aplicaron encuestas así: (a) personal próximo a graduarse de bachiller y recién graduado que corresponden a la categoría de estudiantado joven y (b) personal que terminó el bachillerato hace más de tres años que corresponde a la categoría de estudiantado adulto.

A pesar de las dificultades por la diversidad geográfica y cultural en que se adelantó el trabajo de campo y en la estratificación de las unidades de análisis, se obtuvo la homogeneidad en la selección de la muestra representativa de la población y se consideró suficiente la proporción promedio de 108 encuestas en las regiones en que funcionan 6 de los centros regionales de la FESAD: Boyacá (Tunja, Sogamoso, Nobsa, Duitama. Firavitoba y Ventaquemada), Santander (Barrancabermeja), Cundinamarca (Bogotá, D.C., Fusagasugá, Suba, Engativá, Fontibón, y Bosa), Antioquia (Rionegro y La Ceja), Casanare (Monterrey y Yopal) y Amazonas (Leticia). En total fueron 53 encuestas a estudiantado joven y 55 al adulto, incluyendo proporcionalmente a integrantes de los cuatro segmentos determinados: personas ciegas, sordas, sordo-ciegas y con discapacidad motora.

\section{Instrumentos}

Los ítems de la encuesta estructurada para estudiantado joven, se referían a edad, género, estrato, área de formación predilecta, afinidad con un campo laboral específico y el programa académico que le interesaría estudiar en la Universidad en la modalidad a distancia y virtual. Y para el estudiantado adulto, los ítems de la encuesta fueron además de los anteriores, nivel educativo, estado civil y situación laboral. Para las personas invidentes, la encuesta se aplicó en forma impresa en el lenguaje braille y para las personas con deficiencias auditivas en dos versiones: impresa y digital mediante el traductor a lengua de señas.

\section{Procedimiento}

La encuesta se aplicó al participante por una sola vez, con el fin de evitar riesgos en el ámbito de la salud y psicológicos, y se tuvieron en cuenta, además, las variables socioculturales de la población. El estudio se dividió en tres fases (Tabla 1). 
Tabla 1: Fases de la investigación

Fase

I. Construcción teórica
1. Formulación y verificación de hipótesis

2. Análisis documental: Confrontación de argumento con actores sociales y comunidad científica

3. Elaboración de categorías y subcategorías teóricas y conceptos operativos

4. Antecedentes, límites y proyecciones del estudio

5. Replanteamiento y ajuste de los argumentos
1. Formulación de interrogantes generales desde referentes conceptuales

2. Identificación de la población y selección de la muestra representativa

3. Acopio de información

4. Estructuración y codificación de la información

5. Construcción de argumentos descriptivos

6. Análisis e interpretación de resultados

7. Reconstrucción del texto final con el análisis de los resultados del estudio donde se presenten las conclusiones y recomendaciones

III. Aplicativa
1. Elaboración de matrices para el desarrollo de los materiales educativos de acuerdo con los perfiles de la población objeto de estudio

2. Diseño pedagógico de mecanismos de traducción y transcripción de mensajes a la lengua de señas y al sistema braille

3. Elaboración de prototipos para el diseño gráfico digital de nuevos objetos virtuales de aprendizaje para estudiantes con discapacidad visual, auditiva, del habla y motora

Nota: Elaboración propia. 
doi: http://dx.doi.org/10.15359/ree.22-1.6

URL: http://www.una.ac.cr/educare

CORREO: educare@una.cr

\section{Resultados, análisis e interpretación}

Los siguientes fueron los resultados de la encuesta aplicada al estudiantado joven próximo a graduarse y al estudiantado adulto (Tabla 2).

Se precisa en que los datos estadísticos corresponden a una parte de la muestra dentro del estudio exploratorio, el cual condujo al diagnóstico presentado en este artículo. En esta parte se seleccionaron 108 encuestas de las cuales 55 corresponden a bachilleres en edad adulta y 53 a bachilleres jóvenes. La referencia a los resultados finales del proyecto contemplan otras etapas que se encuentran en desarrollo, por lo cual este es un preliminar que permite a la FESAD trazar una ruta de acción para atender, efectivamente, las necesidades de educación superior en la modalidad a distancia y virtual dentro de la oferta educativa a nivel de pregrado y posgrado de la UPTC.

Tabla 2: Caracterización de la población en situación de discapacidad visual, auditiva, de habla y motora

\begin{tabular}{|c|c|c|c|c|c|c|}
\hline \multirow[t]{2}{*}{ Población registrada } & \multicolumn{2}{|c|}{ Total } & \multicolumn{2}{|c|}{ Bachilleres jóvenes } & \multicolumn{2}{|c|}{ Bachilleres en edad adulta } \\
\hline & $\mathrm{N}$ & $\%$ & $\mathrm{~N}$ & $\%$ & $\mathrm{~N}$ & $\%$ \\
\hline Muestra total & 108 & $100 \%$ & 53 & $49 \%$ & 55 & $51 \%$ \\
\hline \multicolumn{7}{|c|}{ Género } \\
\hline Femenino & 55 & $51 \%$ & 28 & $53 \%$ & 27 & $49 \%$ \\
\hline Masculino & 53 & $49 \%$ & 25 & $47 \%$ & 28 & $51 \%$ \\
\hline \multicolumn{7}{|c|}{ Grupo etario } \\
\hline Menores de 17 años & 13 & $12 \%$ & 13 & $25 \%$ & & \\
\hline Entre 18 y 21 años & 30 & $28 \%$ & 30 & $57 \%$ & & \\
\hline Mayor de 21 años & 10 & $9 \%$ & 10 & $19 \%$ & & \\
\hline Total & 53 & $49 \%$ & 53 & $100 \%$ & & \\
\hline Menor de 21 años & 4 & $4 \%$ & & & 4 & $7 \%$ \\
\hline Entre 22 y 30 años & 26 & $24 \%$ & & & 26 & $47 \%$ \\
\hline Entre 31 y 50 años & 20 & $19 \%$ & & & 20 & $36 \%$ \\
\hline Mayor de 50 años & 5 & $5 \%$ & & & 5 & $9 \%$ \\
\hline Total & 55 & $51 \%$ & & & 55 & $100 \%$ \\
\hline
\end{tabular}

continúa

16 Luz Myrian Rojas-Rojas, Nestor Arboleda-Toro y Leidy Johanna Pinzón-Jaime

Los artículos de la Revista Electrónica Educare del Centro de Investigación y Docencia en Educación de la Universidad Nacional, Costa Rica, se comparten bajo términos de la Licencia Creative Commons: Reconocimiento, № Comercial, Sin Obra Derivada 3.0 Costa Rica. Las autorizaciones adicionales a las aquí delimitadas se pueden obtener en el correo: educare@una.c 


\begin{tabular}{|c|c|c|c|c|c|c|}
\hline \multirow[t]{2}{*}{ Población registrada } & \multicolumn{2}{|c|}{ Total } & \multicolumn{2}{|c|}{ Bachilleres jóvenes } & \multicolumn{2}{|c|}{ Bachilleres en edad adulta } \\
\hline & $\mathrm{N}$ & $\%$ & $\mathrm{~N}$ & $\%$ & $\mathrm{~N}$ & $\%$ \\
\hline \multicolumn{7}{|c|}{ Tipo de discapacidad } \\
\hline Ceguera & 8 & $7 \%$ & 4 & $8 \%$ & 4 & $7 \%$ \\
\hline Sordera & 84 & $78 \%$ & 45 & $85 \%$ & 39 & $71 \%$ \\
\hline Sordera-ceguera & 1 & $1 \%$ & 1 & $2 \%$ & 0 & $0 \%$ \\
\hline Motora & 15 & $14 \%$ & 3 & $6 \%$ & 12 & $22 \%$ \\
\hline Total & 108 & $100 \%$ & 53 & & 55 & $100 \%$ \\
\hline \multicolumn{7}{|c|}{ Estado civil } \\
\hline Unión libre & 5 & $5 \%$ & & N/A & 5 & $9 \%$ \\
\hline Viudo/a & 0 & $0 \%$ & & $\mathrm{~N} / \mathrm{A}$ & 0 & $0 \%$ \\
\hline Casado/a & 12 & $11 \%$ & & N/A & 12 & $22 \%$ \\
\hline Soltero/a & 38 & $35 \%$ & & N/A & 38 & $69 \%$ \\
\hline Total & 55 & $51 \%$ & & & 55 & $100 \%$ \\
\hline \multicolumn{7}{|l|}{ Situación laboral } \\
\hline Trabaja en una empresa o entidad & 19 & $18 \%$ & & N/A & 19 & $35 \%$ \\
\hline No trabaja en una empresa o entidad & 36 & $33 \%$ & & $\mathrm{~N} / \mathrm{A}$ & 36 & $65 \%$ \\
\hline Total & 55 & $51 \%$ & & & 55 & $100 \%$ \\
\hline \multicolumn{7}{|c|}{ Tipo de trabajo } \\
\hline No es trabajador/a independiente & 35 & $32 \%$ & & N/A & 35 & $64 \%$ \\
\hline Es trabajador/a independiente & 20 & $19 \%$ & & $\mathrm{~N} / \mathrm{A}$ & 20 & $36 \%$ \\
\hline Total & 55 & $51 \%$ & & & 55 & $100 \%$ \\
\hline
\end{tabular}

Nota: Elaboración propia. 
doi: http://dx.doi.org/10.15359/ree.22-1.6

URL: http://www.una.ac.cr/educare

CORREO: educare@una.cr

Género de bachilleres: la anterior Tabla 2 evidencia que del grupo de bachilleres jóvenes, el $53 \%$ son mujeres y el $47 \%$ hombres, caso contrario a al grupo de bachilleres en edad adulta en donde hay más hombres con el $51 \%$ en relación con las mujeres con el $49 \%$; sin embargo, esta diferencia en los dos géneros en los dos grupos no es significativa, lo que indica que tanto hombres y mujeres tendrían las misma equidad de género en el momento de inscribirse a un programa de educación superior de la FESAD, pues "una forma efectiva de concretar la inclusión es a través de la educación, vista como un puente que conecta la equidad y la igualdad en las oportunidades" (Delgado-Sanoja y Blanco-Gómez, 2016 p. 5). Sin embargo, conviene precisar que los resultados en materia de género de la población estudiada concuerdan, en general, con la tendencia en este sentido que ha señalado tradicionalmente una composición de estudiantes a distancia de un 53\% de hombres frente a un $47 \%$ de mujeres, la cual tiende a cambiar ya que estudios más recientes muestran que un $60 \%$ de los sujetos matriculados son del género femenino y el $40 \%$ restante corresponde al género masculino.

Rango de edad: Predomina en el grupo adulto el rango que está entre los 22 y 30 años con 47\%; seguido por el de 31 a 50 (36\%); luego con 9\% mayores de 50 y, en último lugar, menores de 21 (7\%). Ahora bien, en cuanto a bachilleres jóvenes, la mayoría (57\%) se encuentra entre los 18 y 21 años, seguido de menores de 17 (25\%) y, en menor cantidad, mayores de 21 (19\%).

El promedio total de edad de la población estudiada es de 26 años, lo cual concuerda con estudios al respecto que permiten establecer la categorización de la población beneficiaria de programas de educación superior a distancia y virtual tanto en el ámbito internacional como en Colombia. Existe una tendencia a la reducción de este promedio que ha sido observada en recientes investigaciones y que también se puede evidenciar en los resultados de este estudio, lo cual se explica por la preferencia de la gente joven al manejo de nuevas tecnologías de la información y la comunicación TIC.

La investigación muestra que hay dos grupos en condición de diversidad funcional cuyas edades son heterogéneas y desde allí se debe contemplar el diseño e implementación de estrategias de educación a distancia y virtual en las cuales se contemple el factor de edad como integrador y no de exclusión, en especial con bachilleres en edad adulta, por el manejo de las herramientas tecnológicas que se deben desarrollar para tal fin.

Tipo de discapacidad: En su mayoría los sujetos bachilleres encuestados presentan la discapacidad de la sordera, en jóvenes en un $85 \%$ y grupos adultos, en un $71 \%$; lo que de entrada muestra un amplio grupo de potenciales estudiantes para los programas que oferta la Facultad de Estudios a Distancia de la UPTC y que la discapacidad con menor porcentaje en bachilleres es la de sordera-ceguera con $2 \%$ en bachilleres jóvenes y $0 \%$ en los grupos adultos.

La discapacidad motora con el $22 \%$ es el segundo tipo en el estudiantado adulto y en bachilleres jóvenes el tercer tipo con 6\%; así mismo, los dos grupos comparten casi el mismo 
porcentaje con el $7 \%$ y $8 \%$ en el tipo de discapacidad "ceguera". Así pues, la responsabilidad y el reto son grandes puesto que se cuenta con una población diversa en cuanto a los tipos de discapacidad. Así las cosas, a pesar de un marco políticamente legitimado de equiparación de oportunidades e inclusión educativa para las personas con discapacidad, "el problema de negligencia con derecho a la educación superior de esta población es severa" (Molina, 2010 p. 95).

Por ende, para una inclusión eficaz deben tenerse en cuenta diferentes líneas como parte del mismo problema, veamos: "la formación universitaria; el trabajo con los equipos docentes al interior de las comunidades educativas, ... el trabajo con los estudiantes al interior de las comunidades educativas; ... el trabajo con padres y apoderados y, finalmente, el trabajo con la sociedad civil (Yupanqui, Aranda, Vásquez y Verdugo, 2014, p. 112).

Desde esta premisa, las directivas de la UPTC y, de manera particular, el personal de FESAD vienen trabajando en la concepción e implementación de una estrategia pedagógica integral con enfoque incluyente, con miras a propiciar el ingreso y graduación de la población vulnerable en condición de discapacidad en cuyo proceso se garantice el conocimiento científico y tecnológico ya que "la educación ha demostrado ser una estrategia fundamental para el cierre de las brechas sociales en diferentes países" (Beltrán-Villamizar, Martínez-Fuentes y Torrado-Duarte, 2015, p. 59).

Estado civil del estudiantado bachiller adulto (no se consultó al grupo de jóvenes): La mayoría son solteros o solteras con un $69 \%$, le siguen los casados o casadas con $22 \%$, luego quienes viven en unión libre, $9 \%$ y $0 \%$ personas viudas.

Situación laboral: El estudiantado adulto, en un 65\% no trabaja y un 35\% sí está laborando. El 64\% no son personas trabajadoras independientes y el $36 \%$ realizan actividades como independientes para obtener ingresos económicos. Aunque las investigaciones sobre caracterización de la población de estudiantes de educación superior a distancia y virtual, en general, demuestra que la mayoría es población adulta que trabaja ( $85 \%$ en promedio), este estudio presenta la tendencia a mostrar que los grupos adultos de la población en situación de discapacidad, no trabaja sino en una mínima parte, lo cual se explica por el nivel de exclusión socioeconómica y laboral que afecta a esta población.

Área de formación preferida: En cuanto a las áreas que prefieren el estudiantado adulto para estudiar están en orden de elección: Ingenierías con $27.3 \%$, ciencias económicas (25.5\%) y administrativas (18.2\%), ciencias de la educación (14.5\%), artes (10.9\%), ciencias de la salud (3.6\%) y en último lugar ciencias agropecuarias con $0 \%$. El estudio arrojó que las áreas de preferencia entre jóvenes bachilleres son: Ingenierías con $28,3 \%$, ciencias económicas y administrativas con $20.8 \%$, artes con $15.1 \%$, ciencias de la educación con $13.2 \%$, otra área con $6 \%$, ciencias de la salud con $9.4 \%$ y, en último lugar, ciencias agropecuarias con $2 \%$. 
doi: http://dx.doi.org/10.15359/ree.22-1.6

URL: http://www.una.ac.cr/educare

CORREO: educare@una.cr

Es así como ingenierías, ciencias económicas, educación y artes son las áreas comunes en la preferencia de jóvenes y personas adultas bachilleres; coincide también en que ciencias de la salud y ciencias agropecuarias son las menos apetecidas (Figura1).

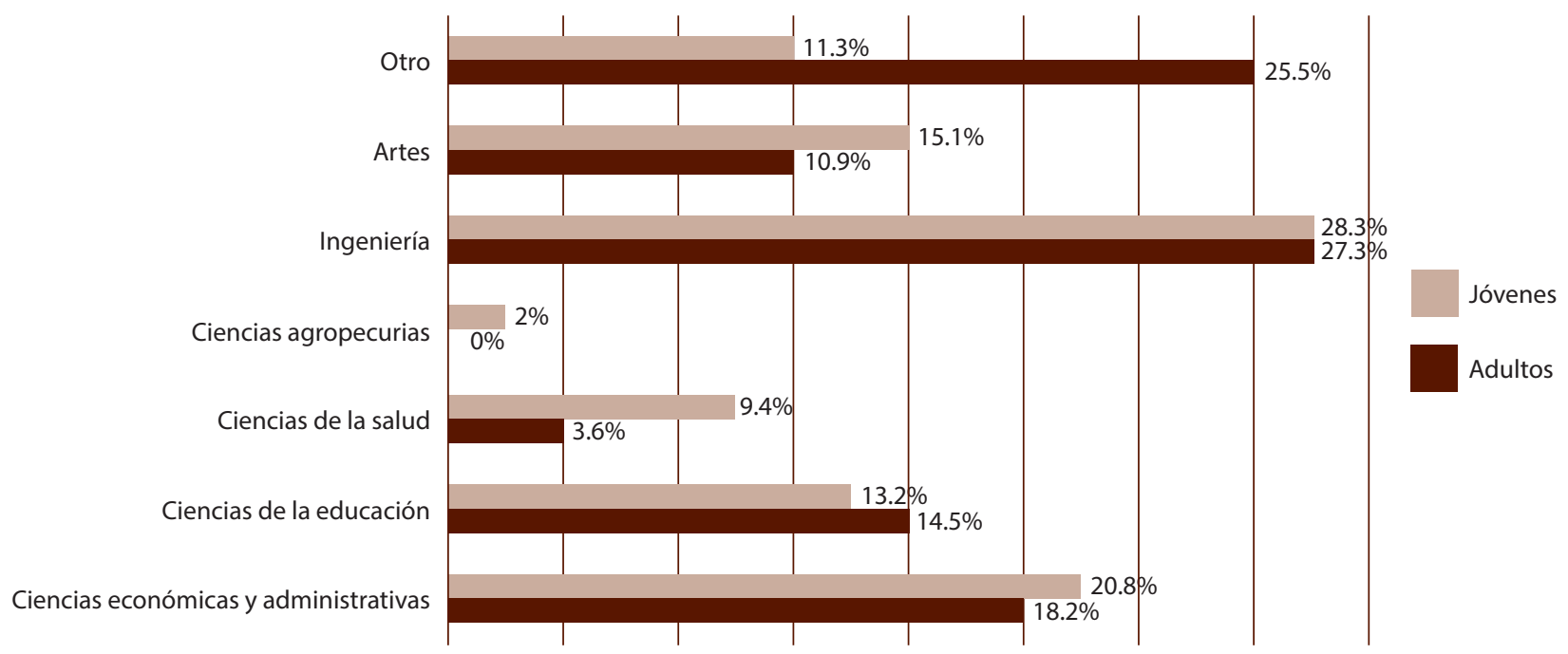

Figura 1. Área de formación preferida por los bachilleres jóvenes y estudiantado adulto.

Nota: Elaboración propia.

Programa de formación preferido: El programa académico de mayor aceptación entre el grupo de jóvenes bachilleres es Licenciatura en Educación Básica con énfasis en Matemáticas, Humanidades y Lengua Castellana (21\%), seguida de Técnico Profesional en Producción Artesanal Sostenible y Tecnología en Gestión Administrativa de Servicios de Salud. También hay una preferencia común con el estudiantado adulto bachiller, en el sentido que también al grupo de jóvenes le atrae la Tecnología en Gestión de Servicios Informáticos. En cambio, el programa académico de mayor aceptación entre estudiantado adulto es Tecnología en Programación de Sistemas Informáticos (23.6\%), luego la Licenciatura en Educación Básica con énfasis en Matemáticas, Humanidades y Lengua Castellana (20\%), seguido por Técnico Profesional en Instalación y Mantenimiento de Redes y Computadores (14.5\%) (Tabla 3). 
Tabla 3: Programa de educación superior ofertado por la FESAD- UPTC que prefieren el estudiantado bachiller y adulto en modalidad distancia y virtual

\begin{tabular}{|c|c|c|c|c|}
\hline $\begin{array}{c}\text { Programas modalidad a distancia y virtual ofertados } \\
\text { por la FESAD-UPTC }\end{array}$ & $\begin{array}{l}\text { Preferencia } \\
\text { Estudiantadojoven }\end{array}$ & $\%$ & $\begin{array}{c}\text { Preferencia } \\
\text { Estudiantado adulto }\end{array}$ & $\%$ \\
\hline $\begin{array}{l}\text { Licenciatura en Educación Básica con Énfasis en } \\
\text { Matemáticas, Humanidades y Lengua Castellana }\end{array}$ & 11 & $21 \%$ & 11 & $21 \%$ \\
\hline $\begin{array}{l}\text { Tecnología en Programación de } \\
\text { Sistemas Informáticos }\end{array}$ & 13 & $24 \%$ & 5 & $9 \%$ \\
\hline $\begin{array}{l}\text { Técnico/a Profesional en Instalación y Mantenimiento } \\
\text { de Redes y Comunicaciones }\end{array}$ & 8 & $15 \%$ & 2 & $4 \%$ \\
\hline $\begin{array}{l}\text { Técnico/a Profesional en } \\
\text { Producción Artesanal Sostenible }\end{array}$ & 6 & $11 \%$ & 7 & $13 \%$ \\
\hline Administración Comercial y Financiera (ciclo profesional) & 5 & $9 \%$ & 2 & $4 \%$ \\
\hline Tecnología en Obras Civiles & 3 & $6 \%$ & 5 & $9 \%$ \\
\hline $\begin{array}{l}\text { Tecnología en } \\
\text { Gestión Administrativa de Servicios de Salud }\end{array}$ & 2 & $4 \%$ & 6 & $11 \%$ \\
\hline Tecnología en Máquinas y Herramientas & 2 & $4 \%$ & 3 & $6 \%$ \\
\hline Tecnología en Regencia en Farmacia & 2 & $4 \%$ & 1 & $2 \%$ \\
\hline Tecnología en Telemática & 1 & $2 \%$ & 3 & $6 \%$ \\
\hline $\begin{array}{l}\text { Tecnología en Gestión de Producción y } \\
\text { Trasnformación del Acero }\end{array}$ & 1 & $2 \%$ & 0 & $0 \%$ \\
\hline Tecnología en Electricidad & 0 & $0 \%$ & 4 & $8 \%$ \\
\hline $\begin{array}{l}\text { Técnico/a Profesional en } \\
\text { Procesos Administrativos de Salud }\end{array}$ & 1 & $2 \%$ & 0 & $0 \%$ \\
\hline $\begin{array}{l}\text { Técnico/a Profesional en } \\
\text { Producción y Transformación del Acero }\end{array}$ & 0 & $0 \%$ & 3 & $6 \%$ \\
\hline Mercadeo Agropecuario (ciclo profesional) & 0 & $0 \%$ & 1 & $2 \%$ \\
\hline Administración de Servicios de Salud (ciclo profesional) & 0 & $0 \%$ & 0 & $0 \%$ \\
\hline Tecnología en Gestión Comercial y Financiera & 0 & $0 \%$ & 0 & $0 \%$ \\
\hline Tecnología en Mercadeo Agropecuario & 0 & $0 \%$ & 0 & $0 \%$ \\
\hline $\begin{array}{l}\text { Técnico Profesional en } \\
\text { Procesos Comerciales y Financieros }\end{array}$ & 0 & $0 \%$ & 0 & $0 \%$ \\
\hline
\end{tabular}

Nota: Elaboración propia. 
doi: http://dx.doi.org/10.15359/ree.22-1.6

URL: http://www.una.ac.cr/educare

CORREO: educare@una.cr

Es interesante observar cómo, en el área de preferencia del estudiantado bachiller joven y adulto seleccionaron ingenierías; sin embargo, cuando se les preguntó sobre el programa que más les llamaba la atención, en primer lugar el grupo de jóvenes y segundo el estudiantado adulto escogieron la licenciatura en Matemáticas, Humanidades y Lengua Castellana que pertenece al área de ciencias de la educación. Así, los proyectos que tiene la FESAD se articulan con la formación pedagógica y se relacionan con la integralidad y complementariedad del conocimiento humano mediante enfoques multidisciplinares, interdisciplinares y transdisciplinares.

\section{Carácter prospectivo y movilizador de la investigación}

\section{En lo social y laboral}

Teniendo en cuenta los resultados del estudio, se concuerda con lo planteado por Infante (2010) cuando expone que se deben abrir espacios en los currículos de las carreras universitarias para reflexionar sobre cuál es enfoque de construcción que cada sujeto elabora sobre inclusión y diversidad, antes de desarrollar las herramientas y las técnicas de trabajo. En correspondencia con este postulado, la FESAD se interesó en cualificar a un grupo de docentes en el diseño de guías de aprendizaje para un currículo inclusivo e incluyente y se trazaron rutas de formación profesional orientadas a las áreas del mercado ocupacional adecuadas al desempeño laboral de la población atendida.

En esta dirección, metodológicamente se busca combinar, de manera creativa, la teoría con la práctica en escenarios laborales consecuentes con el perfil ocupacional contemplado por la Universidad para cada programa académico. Se trata de brindar la oportunidad, al estudiantado, de aplicar lo que aprende en cada uno de los semestres del plan de estudios, procurando no solo familiarizarlo con las exigencias de desempeño de los sectores productivos formales, sino también fomentar el emprendimiento y desarrollo de microempresas que las personas en situación de discapacidad visual, auditiva, del habla y motora, puedan aplicar en su propia casa de manera individual o en pequeños equipos de trabajo con sus pares.

\section{En lo pedagógico y curricular}

Si bien es cierto que la FESAD, a través de la modalidad a distancia y virtual, ha diseñado e implementado estrategias para mejorar cualitativamente la educación superior, la dinámica de desarrollo de este proyecto ha permitido percibir que identificada su ausencia, se deben diseñar estrategias para incluirse en los currículos de los programas académicos que oferta, con el enfoque inclusivo e incluyente para la población vulnerable con discapacidad visual, auditiva,

\footnotetext{
Luz Myrian Rojas-Rojas, Nestor Arboleda-Toro y Leidy Johanna Pinzón-Jaime
}

Los artículos de la Revista Electrónica Educare del Centro de Investigación y Docencia en Educación de la Universidad Nacional, Costa Rica, se comparten bajo términos de la Licencia Creative Commons: Reconocimiento, No Comercial, Sin Obra Derivada 3.0 Costa Rica. Las autorizaciones adicionales a las aquí delimitadas se pueden obtener en el correo: educare@una.cr 
del habla y motora. Por tal razón, es prioritario garantizar una educación integral de calidad para todos y todas y así dar cumplimiento a políticas públicas en educación superior relacionadas con brindar acceso, atención y cobertura a las poblaciones vulnerables desde las instituciones de educación superior y "bajo supervisión directa del MEN [Ministerio de Educación Nacional]" (Beltrán-Villamizar, Martínez-Fuentes y Vargas-Beltrán, 2015, p. 67).

Para cumplir con este propósito, en la fase final aplicativa del estudio se elaboraron los prototipos para el diseño, producción y administración de los cursos virtuales con las características de accesibilidad e inclusión social. Este proceso se adelantó a partir de la matriz de currículo integrado e integrador, de tal manera que contemplara las diversas rutas de aprendizaje y formación práctica, adecuadas a distintos estilos de aprendizaje y orientadas al fomento del emprendimiento y desarrollo micro-empresarial independiente de los cuatro tipos de discapacidad abarcados por la investigación adelantada.

\section{Conclusiones}

Hay un grupo considerable de personas en situación de discapacidad a la espera de que se les garantice con calidad el ingreso a programas de educación superior, ya que en gran medida, sin una formación profesional, se limita su desempeño laboral, característica particular de la exclusión social en Colombia. Sin embargo, el estudio refleja el deseo que tiene esta población de prepararse académicamente y vincularse al campo laboral. Atendiendo lo anterior, en la investigación se trazaron rutas de aprendizaje y formación profesional integral orientadas a las áreas del mercado ocupacional y adecuado al desempeño laboral de la población caracterizada desde la filosofía de la educación a distancia, en donde cada estudiante es gestor o gestora de su propio conocimiento.

Es necesario reconocer que Colombia atraviesa un momento histórico en donde se debe garantizar la igualdad de posiciones y oportunidades en el marco de una cultura de paz, que obliga a todos los sectores de la sociedad a realizar grandes esfuerzos para romper barreras que han impedido la inclusión en el sistema educativo y proceder a concretar acciones reales que conlleven a establecer marcos de valores que efectivicen el derecho a la educación para todas las personas; pues si bien existen políticas educativas para la inclusión por parte del Estado, estas se deben ejecutar y las instituciones educativas deben generar las condiciones para tal fin.

El estudio arrojó que, si bien el área de conocimiento seleccionada por la población objeto de estudio fue ingeniería, el programa académico que más les llamó la atención para adelantar sus estudios de educación superior en la FESAD es la licenciatura en Matemáticas, Humanidades y Lengua Castellana que pertenece al área de ciencias de la educación. 
doi: http://dx.doi.org/10.15359/ree.22-1.6

URL: http://www.una.ac.cr/educare

CORREO: educare@una.cr

Dentro de las soluciones planteadas como respuesta a la problemática abordada por la investigación, la FESAD capacitó a personal docente autor de los objetos virtuales de aprendizaje, con el software de uso libre de la Fundación HETAH (Herramientas Tecnológicas para Ayuda Humanitaria), instalado dentro de la plataforma de la Universidad, que les permite adecuar sus contenidos pedagógicos mediante el Avatar tridimensional para la traducción digital de mensajes a:

- Legua de señas para personas con discapacidad auditiva, y discapacidad auditiva y ceguera.

- Alfabeto braille para personas con discapacidad visual.

- Audiolibros y videos con sensores de reconocimiento táctil y gestual.

Así, los proyectos educativos de la FESAD se articulan con la formación pedagógica y se relacionan con la integralidad y complementariedad del conocimiento humano mediante enfoques multidisciplinares, interdisciplinares y transdisciplinares.

En cuanto al marco normativo de la UPTC (Universidad Pedagógica y Tecnológica, Consejo Superior, 2015) para promover la inclusión educativa y social, el Acuerdo 029 de 2015 es el que actualmente lo reglamenta y define que las líneas de acción son estrategias para el cumplimiento de los objetivos que garantizan el goce efectivo de los derechos de la comunidad upetecista, en los ámbitos personal, familiar, social e institucional, a través de la adaptación curricular, creatividad pedagógica y procesos investigativos. De estas estrategias se resaltan las siguientes:

A. Educación Superior: Proceso de formación permanente, personal, cultural y social que precede a la educación básica secundaria en nivel de pregrado y posgrado como derecho fundamental de todos los ciudadanos garantizando el ingreso, permanencia y graduación.

B. Accesibilidad: Interacción de la persona con el derecho a la información, movilidad y tecnología requeridas para su formación profesional. ...

E. Laboral: Genera oportunidades en igualdad de condiciones mediante acciones de orientación ocupacional, formación para el trabajo, intermediación laboral, fortalecimiento de los emprendimientos a través de la promoción personal y profesional.

F. Fortalecimiento institucional: Compromiso en procesos de Educación Inclusiva para toda la comunidad Upetecista mediante la estructura organizacional y fortalecimiento de los recursos humanos, técnicos y financieros necesarios. (pp. 3-4) 
Aunque Colombia cuenta con la normatividad suficiente para garantizar el derecho a la educación con calidad para esta población, estudios como este muestran la urgencia de diseñar modelos pedagógicos inclusivos en las instituciones de educación superior públicas, pues los niveles de ingreso y permanencia siguen siendo muy bajos. El panorama encontrado se torna alentador, puesto que la población caracterizada tiene estudios de educación media concluidos o próximos a concluirse, por lo cual la UPTC asume el compromiso de seguir avanzando y fortaleciendo sus estrategias institucionales orientadas a dar respuesta satisfactoria al servicio de la inclusión social de personas en situación de discapacidad que están a la espera de obtener una formación profesional con miras a mejorar sus condiciones de vida.

Financiación: Investigación financiada por la Universidad Pedagógica y Tecnológica de Colombia de Tunja en alianza con la Asociación Colombiana de Instituciones de Educación Superior con Programas a Distancia, ACESAD.

Créditos y agradecimientos: Al personal docente de la FESAD que participó en el trabajo de campo, al estudiante semillero de investigación, al investigador externo en su calidad de presidente de la Fundación para el Desarrollo de Herramientas Tecnológicas de Ayuda Humanitaria y a las instituciones estatales que colaboraron con el suministro de información y el permiso para la aplicación de los instrumentos.

\section{Referencias}

Asamblea Nacional Constituyente. (1991). Constitución Política de Colombia (2 ${ }^{\mathrm{a}}$ ed.). Combia: Legis.

Beltrán-Villamizar, Y. I., Martínez-Fuentes, Y. L. y Torrado-Duarte, O. E. (2015). Creación de una comunidad de aprendizaje: Una experiencia de educación inclusiva en Colombia. Encuentros, 13(2), 57-72. doi: https://doi.org/10.15665/re.v13i2.498

Beltrán-Villamizar, Y. I., Martínez-Fuentes, Y. L. y Vargas-Beltrán, Á. S. (2015). El sistema educativo colombiano en el camino hacia la inclusión. Avances y retos. Educación y Educadores, 18(1) 62-75. Recuperado de http://google.redalyc.org/articulo.oa?id=83439194004

Congreso de Colombia. (8 de febrero, 1994). Ley 115 de 1994. Ley general de educación. Diario Oficial 41.214. Recuperado de http://www.alcaldiabogota.gov.co/sisjur/normas/Norma1. jsp?i=292

Congreso de Colombia. (27 de febrero de 2013). Ley Estatutaria 1618 de 2013. Por medio de la cual se establecen disposiciones para garantizar el pleno ejercicio de los derechos de las personas con discapacidad. Diario Oficial N. ${ }^{\circ}$ 48.717. Recuperado de https://docs. supersalud.gov.co/PortalWeb/Juridica/Leyes/L1618013.pdf 
doi: http://dx.doi.org/10.15359/ree.22-1.6

URL: http://www.una.ac.cr/educare

CORREO: educare@una.cr

Consejo Nacional de Educación Superior. (2014). Acuerdo por lo superior 2034. Propuesta de política pública para la excelencia de la educación superior en Colombia en el escenario de la paz. Bogotá: Autor. Recuperado de http://www.dialogoeducacionsuperior.edu.co/1750/ articles-319917 recurso 1.pdf

Delgado-Sanoja, H. D. y Blanco-Gómez, G. (2016). Inclusión en la educación universitaria. Las palabras y experiencias detrás del proceso. Revista Electrónica Educare, 20(2), 1-18. doi: https://doi.org/10.15359/ree.20-2.9

Departamento Administrativo Nacional de Estadística. (2006). Censo general 2005: Discapacidad, personas con limitaciones permanentes. Bogotá: Oficina de publicaciones.

Departamento Nacional de Planeación. (2010). Plan Nacional de Desarrollo2010-2014.Prosperidad para todos. Colombia: Autor.

Dubet, F. (2011). Repesar la justicia social, contra el mito de la igualdad de oportunidades. Buenos Aires: Siglo XXI Editores. Recuperado de http://www.sigloxxieditores.com.ar/pdfs/dubet repensar la justicia social.pdf

Echeita, G. y Ainscow, M. (2011). La educación inclusiva como derecho. Marco de referencia y pautas de acción para el desarrollo de una revolución pendiente. Tejuelo: Didáctica de la lengua y la literatura, 12(1), 26-46. Recuperado de http://mascvuex.unex.es/revistas/index. php/tejuelo/issue/view/153

Gómez, J. C. (2010). Discapacidad en Colombia: Reto para la inclusión en capital humano. Bogotá: Fundación Saldarriaga Concha, Colombia Líder. Recuperado de http://es.slideshare.net/ cristianmaya90/discapacidad-encolombiaretoparalainclusionencapitalhumano

Hernández, R., Fernández-Collado, C. y Baptista, P. (2006) Metodología de la Investigación (Cap. 15, 4ª ed.). México: McGrawHill.

Infante, M. (2010). Desafíos a la formación docente: Inclusión educativa. Estudios Pedagógicos, 36(1), 287-297. doi: https://doi.org/10.4067/S0718-07052010000100016

McMillan, J.y Schumacher, S. (2005). Investigación educativa (5ª ed.). Madrid: Pearson. Recuperado de $\quad$ http://des.for.infd.edu.ar/sitio/upload/McMillan J. H. Schumacher S. 2005. Investigacion educativa 5 ed..pdf

Ministerio de Educación Nacional, Colombia. (10 de diciembre de 2002). Decreto 3020 de 2002, por el cual se establecen los criterios y procedimientos para organizar las plantas de personal docente y administrativo del servicio educativo estatal que prestan las entidades territoriales y se dictan otras disposiciones. Recuperado de http://www.mineducacion.gov.co/1621/ articles-104848 archivo pdf.pdf 
Ministerio de Educación Nacional, Colombia. (9 de febrero de 2009). Decreto 366. Por medio del cual se reglamenta la organización del servicio de apoyo pedagógico para la atención de los estudiantes con discapacidad y con capacidades o con talentos excepcionales en el marco de la educación inclusiva. Recuperado de http://www.mineducacion.gov.co/1621/ articles-182816 archivo pdf decreto 366 febrero 9 2009.pdf

Ministerio de Educación Nacional, Instituto Nacional para Ciegos e Instituto Nacional para Sordos. (2012). Orientaciones generales para la atención educativa de las poblaciones con discapacidad en el marco del derecho a la educación. Bogotá: Autor. Recuperado de http:// www.colombiaaprende.edu.co/html/micrositios/1752/articles-320765 Pdf 2.pdf

Molina, R. (2010). Educación superior para estudiantes con discapacidad. Revista de Investigación, 34(70) 95-115. Recuperado de http://www.redalyc.org/pdf/3761/376140385005.pdf

Organización de las Naciones Unidas. (13 de diciembre de 2006). Convención sobre los derechos de las personas con discapacidad y protocolo facultativo. Recuperado de http://www. un.org/disabilities/documents/convention/convoptprot-s.pdf

Organización Mundial de la Salud. (2001). Clasificación internacional del funcionamiento, de la discapacidad y de la salud, CIF (Versión abreviada). Recuperado de http://apps.who.int/iris/ bitstream/10665/43360/1/9241545445 spa.pdf

Organización Mundial de la Salud y Banco Mundial. (2011). Resumen informe sobre mundial sobre discapacidad. Ginebra: Autor. Recuperado de http://www.who.int/disabilities/ world report/2011/summary es.pdf

Parra, C. (2011). Educación inclusiva: Un modelo de diversidad humana. Revista Educación y Desarrollo Social, 5(1), 139-150. Recuperado de https://revistas.unimilitar.edu.co/index. $\mathrm{php} / \mathrm{reds} / \mathrm{article} / \mathrm{view} / 897 / 648$

Presidencia de la República de Colombia. (18 de noviembre de 1996). Decreto 2082 de 1996. Por el cual se reglamenta la atención educativa para personas con limitaciones o con capacidades o talentos excepcionales. Recuperado de http://www.mineducacion.gov.co/1759/ articles-103323 archivo pdf.pdf

Romañach, J. y Lobato, M. (Mayo de 2005). Diversidad funcional, nuevo término para la lucha por la dignidad en la diversidad del ser humano. Foro de vida independiente. España. Recuperado de http://centrodocumentaciondown.com/documentos/\%20show/doc/1347/from

Salazar, R. J. y Melo, Á. L. (2013). Lineamientos conceptuales de la modalidad de educación a distancia. En N. Arboleda y C. Rama (Eds.), La educación superior a distancia y virtutal en Colombia: Nuevas realidades (pp. 81-111). Bogotá, Colombia: ACESAD. Recuperado de http://virtualeduca.org/documentos/observatorio/la educacion superior a distancia y virtual en colombia nuevas realidades.pdf 
doi: http://dx.doi.org/10.15359/ree.22-1.6

URL: http://www.una.ac.cr/educare

CORREO: educare@una.cr

Sarmiento, A. (2011).Situación delaeducación en Colombia. Preescolar, básica, mediaysuperior. Una apuesta al cumplimiento del derecho a la educación para niños, niñasyjóvenes. Bogotá:Azoma Criterio Editorial. Recuperado de https://issuu.com/educacioncompromisodetodos/ docs/273a1 situacion-educacion-tercera-edicion

Secretaría Jurídica Distrital de la Alcaldía Mayor de Bogotá. (31 julio, 2009). Ley 1346 de 2009. Por medio de la cual se aprueba la "Convención sobre los Derechos de las Personas con Discapacidad", adoptada por la Asamblea General de las Naciones Unidas el 13 de diciembre de 2006. Diario Oficial 47427. Recuperado de http://www.alcaldiabogota.gov. co/sisjur/normas/Norma1.jsp?i=37150

Serrano, C. P. y Camargo, D. M. (2011). Políticas de inclusión educativa del discapacitado. Barreras y facilitadores para su implementación: Bucaramanga, 2010. Revista Facultad Nacional de Salud Pública, 29(3) 289-298. Recuperado de http://www.redalyc.org/articulo. oa?id=12021452009

Universidad Pedagógica y Tecnológica de Colombia, Consejo Superior. (26 de mayo de 2015). Acuerdo N. 029 de 2015. Por el cual se adopta la política institucional de educación inclusiva, para la Universidad Pedagógica y Tecnológica de Colombia. Recuperado de http://www. uptc.edu.co/export/sites/default/secretaria general/consejo superior/acuerdos 2015/ Acuerdo 029.pdf

Yupanqui, A., Aranda, C. A., Vásquez, C. A. y Verdugo, W. A. (2014). Educación inclusiva y discapacidad:Su incorporación en la formación profesional de la educación superior. Revista de la Educación Superior, 43(171), 93-115. doi: https://doi.org/10.1016/j.resu.2014.06.003 